Nadezhda Kaluizhnova, Mihail Osipov

Irkutsk State University, Russia

\title{
Institutional factors of innovation-oriented regional development
}

It is important to find incentives for economic development in the post-crisis situation. In the Russian context, as in many other countries, the economic development is complicated by the need to mitigate the significant regional imbalances of development, to form the missing but essential market segments, and to develop the economic and social infrastructure.

The institutional environment of the economy is an important aspect of ensuring development. There are functioning institutions whose purpose is to implement policies aimed at removing barriers which prevent the development and competitiveness of countries and regions and to mitigate the disparities on the one hand. On the other hand, it is possible to form a system of special institutions stimulating development - the development institutions. But creation of effective development institutions is impossible without studying mechanisms of interaction between these institutions and the national economy.

Institutions of development are specialized organizations primarily created and funded by the state or public organizations for supporting business projects of high economic or social significance, also by granting long-term funding sources.

Currently existing development institutions carry out a wide range of tasks. These are institutions for small and medium business, mortgage funds, venture capital and guarantee funds, special economic zones, industrial parks, etc (http://www.raexpert.ru).

Development institutions should stimulate economic growth and, to this end, enhance the economic competitiveness of countries. However, the measurement of the institutions and their economic efficiency is a scientific challenge. According to our preceding research on the impact of their activities on economic performance (Калюжнова Н.Я., Осипов М.А. 2011), the effect of development institutions is mixed. A number of Russian institutions successfully cope with their problems but others are less successful.

The development of the institutional market relations in the sphere of science technology and innovation are caused by the trends of economic development in post-industrial society. However, Russia continues to lag behind the developed countries to date, despite recognition at the state level of the necessity of transition to innovative development. The high degree of depreciation of fixed assets in several industries continues to grow. Many important problems have not been solved yet, such as modernization of the national power grid. There 
is large backlog in important areas, such as information technology, biotechnology, new materials, etc.

Moreover, it is possible to note a problem of intellectual property protection, as legal protection of intellectual activity is an essential element of innovation policy, necessary for the spread of market relations in the field of science. But to date the level of legal protection remains low. That leads to a situation when much of the scientific production goes to foreign countries.

Therefore the problems of development and restructuring of the state scientific-technical sphere are now discussed widely at different levels, the state innovation policy, measures of the government support and incentives for science, technology and innovation, issues of legal, organizational, informational, and personnel support for innovation, and formation of the innovation system in the Russian Federation.

But the innovative economy will not arise by itself. The graphs below show that the innovative activity of organizations of regions is weakly dependent on the value of the gross regional product per capita (fig. 1):

In connection with the above, the innovative development institutions deserve special attention. The country's position in the world and its competitiveness more than before depends on the ability to adapt to economic changes, which are primarily dependent on the level of technology, and that enhances the need to create institutions to stimulate the development of innovation in the context of globalization. These institutions should become a co-organizer and main sources of financing large-scale innovative projects aimed at developing technologies, including defining the national security and strategic competitive position in Russia.

State intervention in innovative processes is caused by the necessity to create incentives for innovation, which is not generated sufficiently by the market environment. Particularly it is necessary to compensate "market failures" which are caused by the following factors (Кузык М., Симачев Ю. 2010):

- Inability of the market to provide comprehensible to innovative breaks coordination between science and business and between various segments in the innovative sphere and the corporate sector.

- The limited capacity of small and medium-sized innovative businesses to the concentration of resources required for implementation of projects.

- High information uncertainty and high risk "free-rider problem", which is manifested in the fact that the risks are borne by the innovator, while a large part of winning goes to the "imitators".

- The non-profit stage in the development of innovative project is long, which is discouraging for private investors.

The necessity to compensate these failures dictates the main tasks of institutions supporting innovative development. They are: reducing the risk of innovative private investment, promoting innovation in the non-profit stages of development, aid to small and medium innovation businesses, and ensuring coordination between research institutions and innovative companies and business.

Our preliminary analysis and assessment of global experience of the functioning of development institutions allows us to draw several important conclusions regarding the optimal configuration and possible ways to improve Russian institutes. 


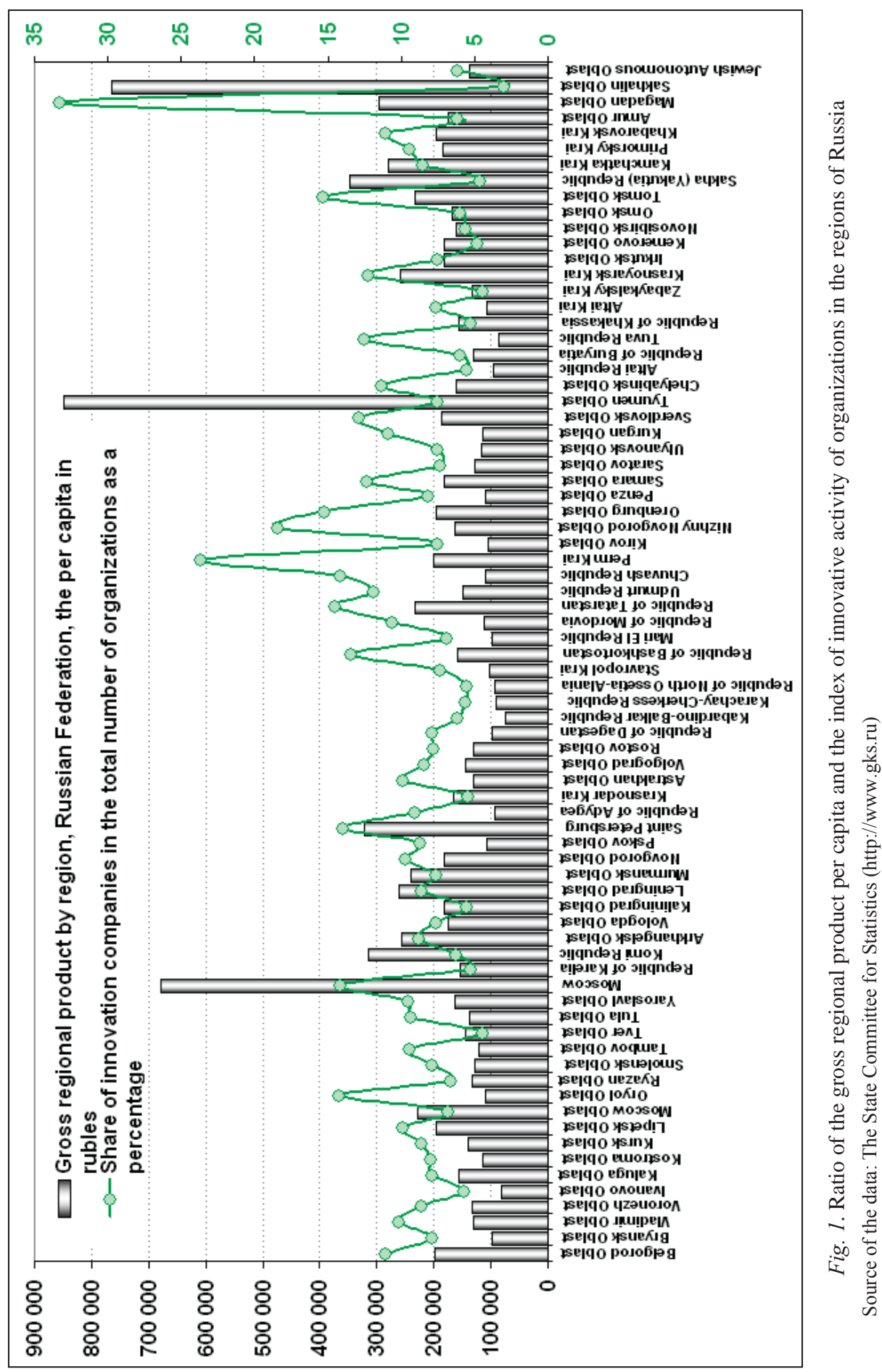




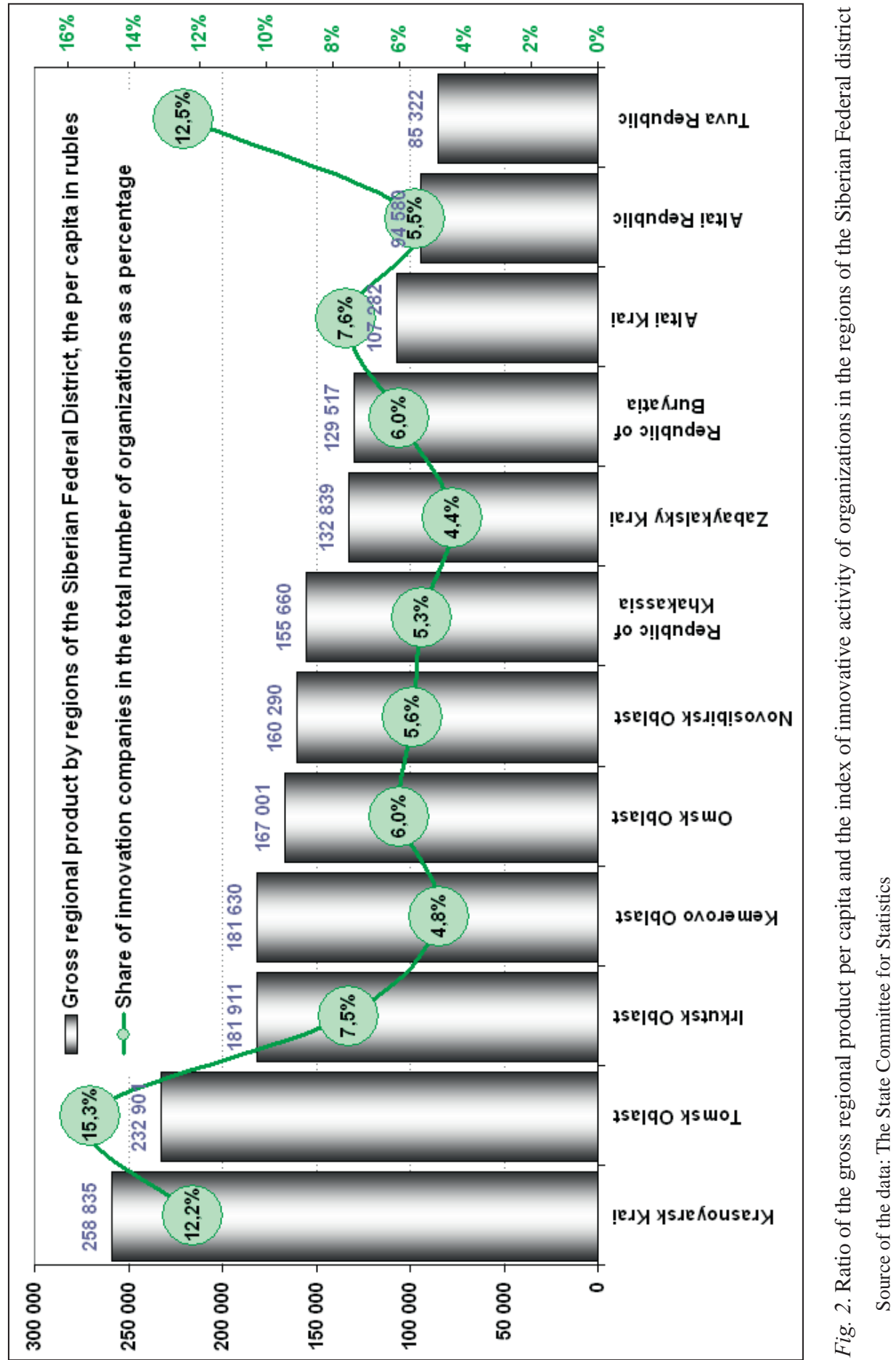


The system of support institutions should be comprehensive, i.e. cover the "market failure" at all stages of the innovation where it occurs. Otherwise, inevitably, there will be "bottlenecks" hindering the promotion of innovative businesses. It is necessary to create parallel institutions aimed at different groups of participants at different stages of the process of solving the problems of innovative business development.

Discussing the currently existing institutions of innovative development, it may be admitted that the innovative development institutions include non-profit organizations created to attract public and private financial resources to developing new markets, innovation, and support for promising innovative projects and small innovative companies. The venture capital funds, science and technology parks and business incubators at universities and major research institutes, supported both by the state and private business are the classic examples of such innovation-oriented institutions. In addition, the government programs supporting innovation at both the federal and municipal level play an important role in forming the innovative development institutions.

There are also the non-financial institutions, such as industrial parks, an agency of the regional and municipal development, and others, which take a very modest place, being at the same time a sufficient demand in the modern Russian system of institutions. They have greater protection from the risks of corruption when compared to the development of financial institutions, in addition by the virtue of the structure of services.

Talking about the currently existing Russian innovatively oriented institutions, it is possible to allocate the following three groups of active institutions having considerable resources:

- A group of so-called seed funds includes institutions focusing on funding innovative companies in the earliest stages, in amounts generally not exceeding 30 million rubles. The group included Promoting Fund and Seed Fund of the Russian Venture Company.

- A group of venture funds which consists of institutions designed to organize and carry out venture financing concerning young companies. This could include a variety of regional venture capital funds and the Russian venture company with a system of venture funds selected and financed by it. The support provided by the funds of the group ranges from tens to hundreds of millions of rubles.

- The group of corporations and development banks is formed by the government-owned corporation Rusnano and Vnesheconombank, mainly focusing on support offered to investment projects of the companies at later stages (more so for Vnesheconombank) in very large volumes: RUSNANO - up to several billion rubles, the Development Bank - up to tens of billions.

A little isolated position is occupied by the Russian Development Bank, with the primary goals of providing access to small and medium-sized to medium- and long-term financial resources for the whole territory of Russia. Above all the regions lack the resources to providing support to enterprises production sphere??? as well as companies that implement innovative and high-tech projects. Due to the fact that the Russian Bank for Development is focused on supporting small and medium-sized enterprises, the amounts provided to them are relatively small - about 10 million rubles. However, the bank is not focused on supporting companies in the early stages of their life cycle.

Frameworks of functioning of these institutions are diverse: their work is aimed at supporting innovative activities of both small and medium-sized firms and large companies. 
They focus on different stages of innovation, from the „seed”, early, and later, and use a variety of support mechanisms: grants, investments, loans, etc. In certain areas various models of stimulation of innovations are realized. Thus to support projects at an early stage, now, the after creation of Seed Fund of the Russian Venture Company, the investment scheme in the capital of the companies is used along with the grant mechanism. Support for venture capital projects through the model is implemented as a „fund of funds," and on the basis of the mechanism of the policy, support is given to the establishment of regional venture capital funds (both models suggest the involvement of business and in the regional venture capital funds - money of the regions).

Indicators to assess the innovative activity and, as a consequence, the effectiveness of the innovative development institutions may include:

- Sales of innovative products and services including goods, work or services exposed to all sorts of technological change over the past three years.

- Level of innovative activity of organizations, which is determined as the ratio of the number of organizations implementing technological innovation in the total number of the organizations surveyed, calculated as a percentage.

- The number of patents granted for inventions, utility models, industrial designs and other results of innovation.

- Expenditure on technological innovation.

As an example, consider the activities of 22 regional venture capital investments in small enterprises in scientific-technical sphere, carried out in 2006-2010 by the Ministry of Economic Development in cooperation with regional administrations and now in cooperation with the Russian Venture Company. The total amount is 9.2 billion rubles. As trustees of these funds include representatives of the Russian Venture Company, for all of the projects that are competitors for investments of the regional venture capital funds it is compulsory to undergo examination in the Russian Venture Company.

Thus in 2010 the average duration of the existence of the Regional Venture Fund is accounted for more than 2 years, which have passed in rather turbulent economic times. But even in such a short period of time the following can be noticed:

- The number of advanced technologies developed for the year considered in a region increased on average by 7.5 units.

- The number of patents granted on inventions for the year considered in a region increased on average by 136 units.

- The number of patents granted on utility models for the year considered in a region increased on average by 33.5 units.

These data suggest the effectiveness of these organizations.

Thus to date a fairly wide range of innovative development institutions have been formed. Some of them have significant resources, demonstrate some flexibility and are active in improving their operations. The study of the experience of other countries shows that in some countries innovative development institutions have extremely strong influence on the formation and development of the innovative sector. But the degree of influence of these institutions on the national economies of different countries and regions may vary. Also there is still the question of the possibility and expediency of loans of institutes of innovative development from other countries, and it can be considered in the way of possibilities of borrowing institutions from other institutional environments in general. 


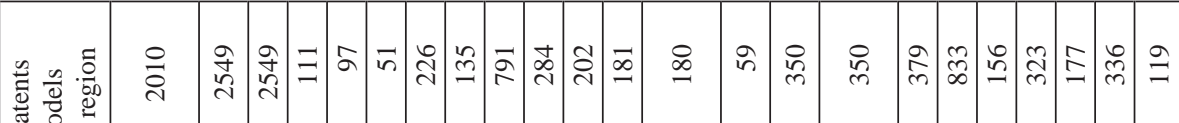
矛施

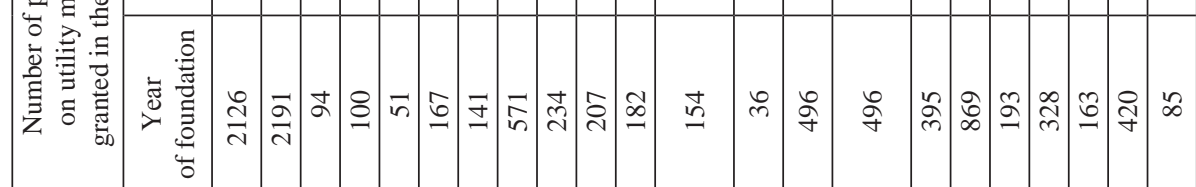

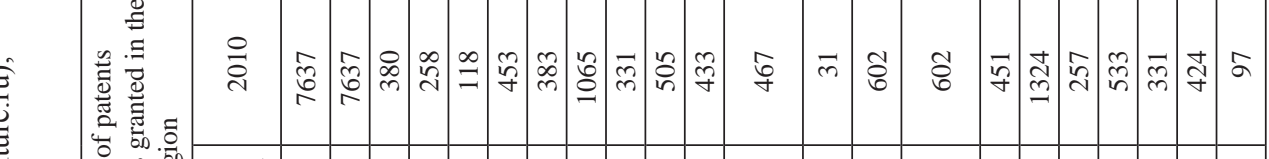
节

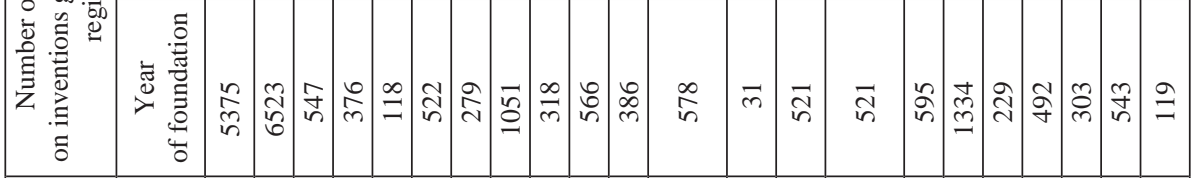

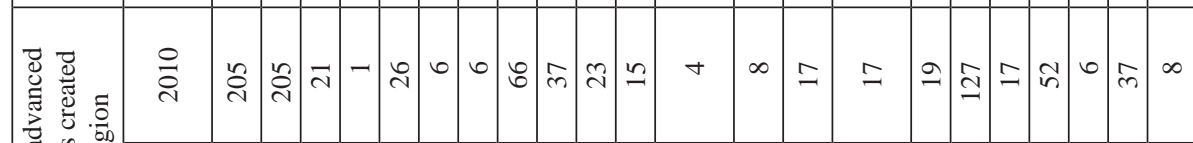

농

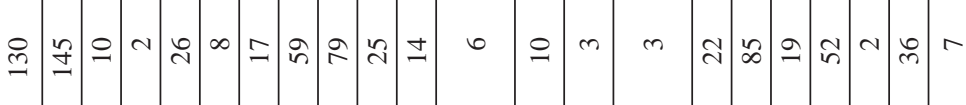

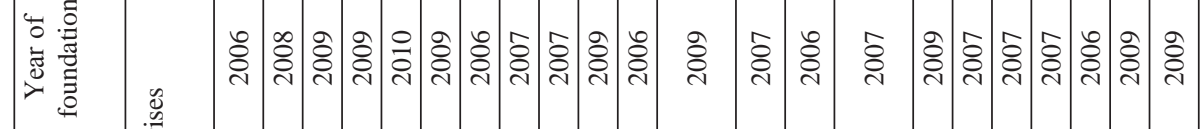

可㺃

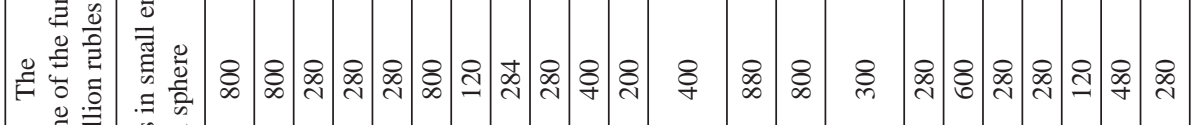

है

8

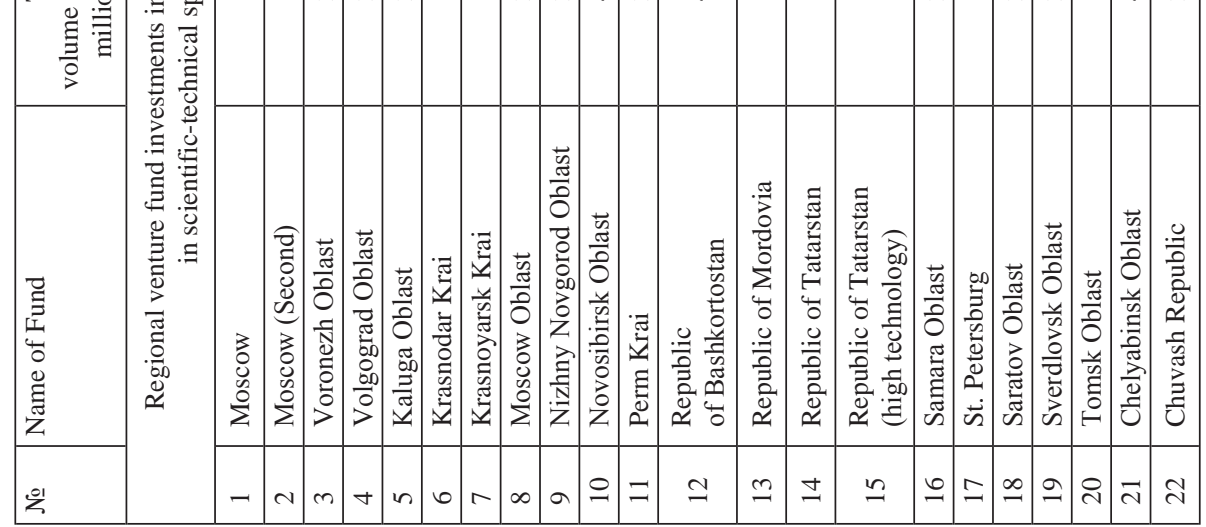




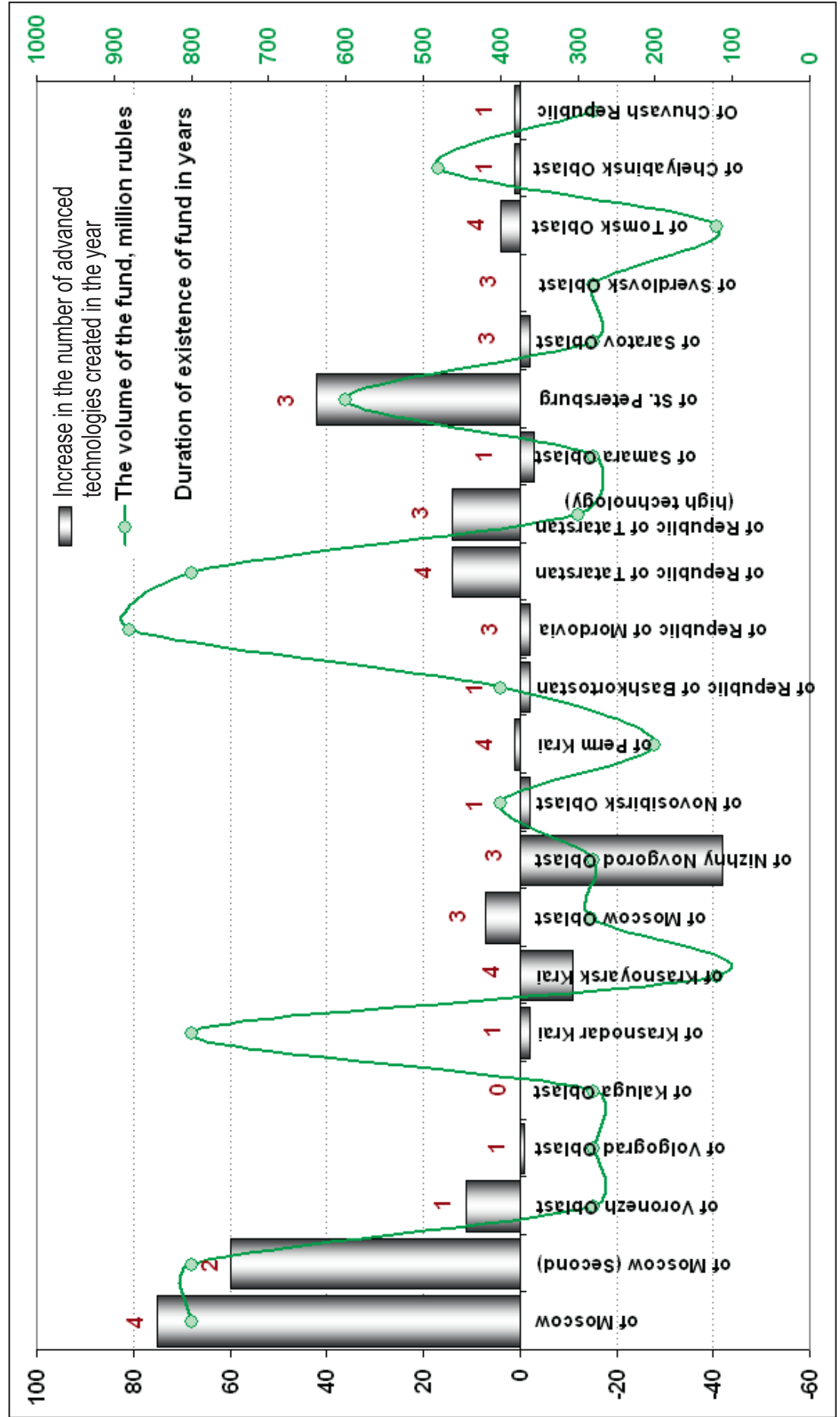




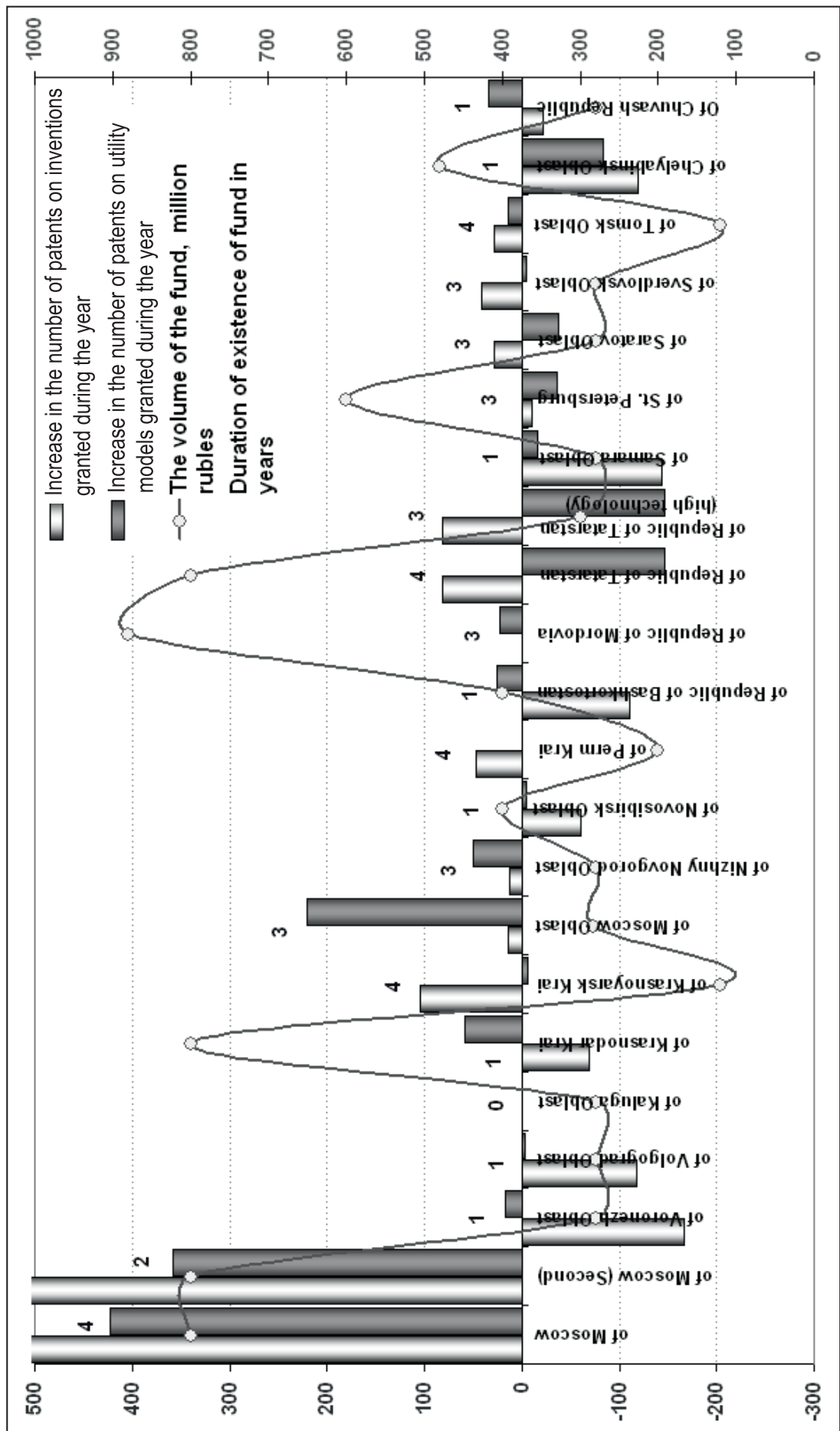


Below, we show how these funds impact on the number of established technologies and the number of patents granted (fig. 3).

However, now we can say with confidence that study of such institutions and their influence on the innovative development, conducted on the examples of specific economies, is an area which urgently calls for research in the emerging innovation society.

\section{References}

Волков С., Доронкин М., Горбунов и др А., Российские институты развития: региональный аспект // Website Expert RA, http://www.raexpert.ru/researches/regions/ros_evolution/part3/

Калюжнова Н.Я., Осипов М.А., 2011, Оценка влиятельности институтов регионального развития // Вестник ИРГТУ, № 4, с. 145-153.

Website of the State Committee for Statistics - section „Science and Innovation”, http://www.gks. $\mathrm{ru} / \mathrm{wps} / \mathrm{wcm} / \mathrm{connect/rosstat/rosstatsite/main/enterprise/science/ \#}$

Кузык М., Симачев Ю., 2010, Институты в развитии // Прямые инвестиции. № 4 (96), с. 16-21.

Website of the Russian Venture Company, http://www.rusventure.ru/ru/investments/regional_funds/

\section{Institutional factors of innovation-oriented regional development}

In the article, the problem of identification of institutes of innovation-oriented regional development is discussed. The role of an institute is considered in the concept of competitiveness of the region. Institutional systematization, including institutes of the regional development, is discussed, as well as the building of the models of regression dependencies between institutes of regional development and indicators of the processes for the stimulation of which they are created. The conclusion is made about the presence or absence of the influence that the fund has upon some indicators of regional development.

Prof. dr Nadezhda Kaluizhnova

Irkutsk State University

e-mail: nk@home.isu.ru

Mihail Osipov

Irkutsk State University

e-mail: osipovmisha@yandex.ru 